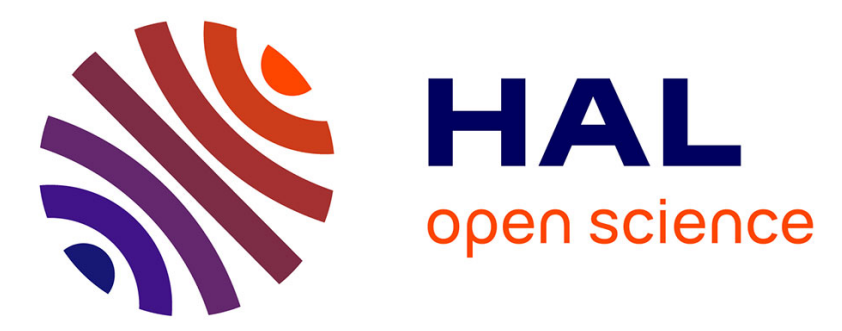

\title{
Statistical assessment of the preferred longitudinal bands for recent geomagnetic reversal records
}

\author{
C. Laj, A. Mazaud, R. Weeks, M. Fuller, E. Herrero-Bervera
}

\section{To cite this version:}

C. Laj, A. Mazaud, R. Weeks, M. Fuller, E. Herrero-Bervera. Statistical assessment of the preferred longitudinal bands for recent geomagnetic reversal records. Geophysical Research Letters, 1992, 19 (20), pp.2003-2006. 10.1029/92GL02164 . hal-03583701

\section{HAL Id: hal-03583701 \\ https://hal.science/hal-03583701}

Submitted on 22 Feb 2022

HAL is a multi-disciplinary open access archive for the deposit and dissemination of scientific research documents, whether they are published or not. The documents may come from teaching and research institutions in France or abroad, or from public or private research centers.
L'archive ouverte pluridisciplinaire HAL, est destinée au dépôt et à la diffusion de documents scientifiques de niveau recherche, publiés ou non, émanant des établissements d'enseignement et de recherche français ou étrangers, des laboratoires publics ou privés. 
GEOPHYSICAL RESEARCH LETTERS, VOL. 19, NO. 20, PAGES 2003-2006, OCTOBER 23, 1992

\title{
STATISTICAL ASSESSMENT OF THE PREFERRED LONGITUDINAL BANDS FOR RECENT GEOMAGNETIC REVERSAL RECORDS.
}

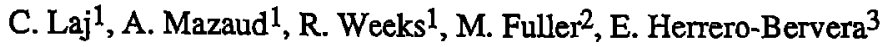

\begin{abstract}
Records of recent polarity reversals recorded in sediments show a preponderance of transitional VGP's situated in the longitudinal sector over the Americas and, to a lesser extent, over its antipode. A series of tests based on the methods of circular statistics show that this distribution is not consistent with the statistical fluctuations of a random probability distribution. The longitudinal bias in the distribution, therefore, requires a physical explanation.
\end{abstract}

\section{Introduction}

It has recently been observed that the virtual geomagnetic poles (VGP) during a reversal are preferentially situated in the longitudinal sector over the Americas and, to a lesser extent, over its antipode [Clement, 1991; Tric et al., 1991a]. This observation has led to the suggestion that VGP paths during reversals may reveal motions in the Earth's core which may themselves be linked to the thermal structure of the lower mantle and possibly to plate tectonics [Laj et al., 1991]. However, Valet et al. [1992] argue that the visual impression of two preferential bands is not sustained by a statistical analysis, while Langereis et al. [1992] argue that the preponderance of paths over the Americas and its antipode may be due to an artifact of sedimentary magnetization arising from smoothing of pre- and post-transitional directions. Therefore, before any physical meaning is attached to the two preferential longitudinal bands, these two issues must be further discussed. In this letter, we address the first question. The question of smoothing by sedimentary magnetization acquisition is considered elsewhere [Weeks et al., this volume].

\section{The database}

To establish a database of reversal records, a set of criteria for reliability is used to select the records. The general criteria we use here, publication in refereed journals, presence of at least 4-5 transitional directions and existence of reasonable laboratory analyses, are basically the same used by Tric et al. [1991a], and by Valet et al. [1992]. They are similar to those suggested more than 10 years ago by Fuller et al. [1979]. Despite the accumulation of new results in recent years, much more stringent criteria would result in a very small number of usable records.

We have considered records of reversals with ages up to 12 my, and have also included the records of the Blake, Cobb,

\footnotetext{
1 - Centre des Faibles Radioactivités, CEA-CNRS, Gif-surYvette, France

2- University of California Santa Barbara, USA

3 - University of Hawaii, USA
}

Copyright 1992 by the American Geophysical Union.

Paper number 92GL02164

0094-8534/92/92GL-02164\$03.00 and Gilsa events, because it seems to us that they are well established short polarity chrons with worldwide character [Tric et al., 1991b]. We did not consider records from intrusions or lavas. Records from intrusions are particularly susceptible to severe field averaging due to long acquisition times of magnetization, and there are very few lava records of polarity reversals. Moreover, it is difficult to define VGP paths for volcanic records of reversals, because they give in most cases scattered spot readings of the field. So, we discuss these records separately. The resulting database is shown with references in Table 1.

To characterize the longitudinal position of the records with a single parameter in a form suitable for the statistical analysis, we have considered their equatorial crossings, which were determined by averaging the longitudes of the transitional VGPs situated in a $60^{\circ}$ latitudinal band centered over the equator. For the same records, they are not significantly different from the Mean VGP Longitudes (MVL) reported by Valet et al. [1992]. The distribution of equatorial crossings is shown in Figure 1a. Some records are more detailed than others, but we have given equal weight to all the reliable records in the statistical analysis.

\section{Statistical methods}

To test whether the visual preponderance of VGP paths over the Americas or its antipode may arise from statistical fluctuations of a uniform random distribution or not, we have used standard methods of circular statistics. These methods are specifically designed for the analysis of data distributed on a circle and do not require any a-priori partitioning of the data into longitudinal bins, thus avoiding subjective choices of the width and position of intervals on the circle. In addition, these methods allow to judge whether a given non-random circular distribution is unimodal or bimodal. This is particularly relevant here because we want to test the hypothesis that there are two antipodal preferred bands of longitude. Three of the most commonly employed methods are used here: the Watson, Rao and Rayleigh tests. In all tests, the null hypothesis is that the given distribution is drawn from a uniform random process. When the probability $\gamma$ of drawing the given data sample from a uniform distribution was less than 0.05 , this hypothesis was rejected. To test for bimodality we have used the technique of doubling the angles. When all the angles are doubled and the multiples reduced modulo $360^{\circ}$, a bimodal axial distribution is transformed into a unimodal circular sample to which usual circular tests can be applied. A uniform distribution will, on the contrary, remain uniform upon doubling the angles. The effect of doubling the angles on our set of equatorial crossings is shown in Figure $1 b$.

Watson's $\mathrm{U}^{2}$ test is convenient for unimodal and multimodal distributions and is particularly well suited for small sample sizes. When the sample value of the statistics $U^{2}$ exceeds critical values given in tables, the null hypothesis is 
Table 1. The considered records, their equatorial crossings and site coordinates.

\begin{tabular}{|c|c|c|c|c|c|c|}
\hline Authors & Path name & Eq. crossings & Site/core & Site long. (E) & lat. & References \\
\hline $\begin{array}{l}\text { H-B* et al. } \\
\text { Tric et al. } \\
\text { Clement \& Kent } \\
\text { Clement et al. } \\
\text { Clement et al. } \\
\text { Valet et al. } \\
\text { Valet et al. } \\
\text { Theyer et al. } \\
\text { Clement \& Kent } \\
\text { Koci and Sibrav } \\
\text { Niitsuma } \\
\text { H-B* \&Theyer } \\
\text { H-B* \&Theyer } \\
\text { Gee et al. } \\
\text { Gee et al. } \\
\text { Clement \& Kent } \\
\text { Clement \& Kent } \\
\text { Gurarii } \\
\text { Clement } \\
\text { Clement \& Kent } \\
\text { Clement \& Kent } \\
\text { Clement \& Kent } \\
\text { H-B* \& Khan } \\
\text { Tric et al. } \\
\text { Clement \& Kent } \\
\text { Ruocco } \\
\text { H-B* \& Theyer } \\
\text { H-B** et al. } \\
\text { Liddicoat } \\
\text { Burakov et al. } \\
\text { Ruocco } \\
\text { Linssen } \\
\text { Linssen } \\
\text { Linssen } \\
\text { Valet \& Laj } \\
\text { Valet \& Laj } \\
\text { Valet \& Laj } \\
\text { Valet \& Laj } \\
\text { Laj et al. } \\
\text { Laj et al. } \\
\text { Laj et al. }\end{array}$ & $\begin{array}{l}\text { Blake event } \\
\text { Blake event } \\
\text { Brunhes-M } \\
\text { Brunhes-M } \\
\text { Brunhes-M } \\
\text { Brunhes-M } \\
\text { Brunhes-M } \\
\text { Brunhes-M } \\
\text { Brunhes-M } \\
\text { Brunhes-M } \\
\text { Brunhes-M } \\
\text { Up Jaramillo } \\
\text { Low Jaramillo } \\
\text { Low Jaramillo } \\
\text { Low Jaramillo } \\
\text { Low Jaramillo } \\
\text { Low Jaramillo } \\
\text { Low Jaramillo } \\
\text { Cobb event } \\
\text { Cobb event } \\
\text { Gilsa event } \\
\text { Up Olduvai } \\
\text { Up Olduvai } \\
\text { Up Olduvai } \\
\text { Up Olduvai } \\
\text { Up Olduvai } \\
\text { Low Olduvai } \\
\text { Low Olduvai } \\
\text { Gauss-Matuyama } \\
\text { Gauss-Matuyama } \\
\text { Gauss-Matuyama } \\
\text { Up Mammoth } \\
\text { Up Nunivak } \\
\text { Up Thvera } \\
\text { KP102 } \\
\text { KS 06 } \\
\text { KS 05 } \\
\text { KS 02 } \\
\text { ZM 03 } \\
\text { ZM 02 } \\
\text { ZM 01 }\end{array}$ & $\begin{array}{r}300 / 170 \\
120 / 280 \\
280 \\
250 / 120 \\
170 \\
220 \\
75 \\
140 \\
295 \\
305 \\
120 \\
285 \\
270 \\
270 \\
180 \\
160 \\
210 \\
300 \\
360 / 180 \\
330 / 200 \\
360 / 310 \\
30 \\
290 \\
280 \\
120 / 300 \\
290 \\
230 \\
270 \\
325 \\
120 \\
290 \\
210 \\
300 \\
90 / 280 \\
180 \\
290 \\
110 \\
300 \\
140 \\
120 \\
360 / 300\end{array}$ & $\begin{array}{l}\text { Westem USA } \\
\text { Mediterranean } \\
609 \mathrm{~b} \\
\text { V20107 \& } 108 \\
\text { RC1521 } \\
\text { Lake Tecopa } \\
664 d \\
78019 \\
\text { V1658 } \\
\text { Bruggen } \\
\text { Boso Peninsula } \\
78030 \\
78030 \\
665 \text { A } \\
758 B \\
609 b \\
\text { RC1414 } \\
\text { Central Asia } \\
\text { Labrador sea } \\
\text { 609b } \\
609 b \\
\text { RC1414 } \\
7501 \\
\text { Italy } \\
609 b \\
\text { Argentina } \\
76113 \\
78019 \\
\text { California } \\
\text { Turkmenia } \\
\text { Argentina } \\
\text { Sicily (Italy) } \\
\text { Calabria (Italy) } \\
\text { Sicily (Italy) } \\
\text { Crete (Greece) } \\
\text { Crete (Greece) } \\
\text { Crete (Greece) } \\
\text { Crete (Greece) } \\
\text { Northem Greece } \\
\text { Northem Greece } \\
\text { Northem Greece }\end{array}$ & $\begin{array}{c}238.6 \\
33 / 13 \\
335 \\
180 \\
228 \\
243 \\
337 \\
189 \\
31 \\
6.3 \\
140.3 \\
199.7 \\
199.7 \\
340 \\
90 \\
335 \\
60 \\
80 \\
315 \\
335 \\
335 \\
60 \\
179.3 \\
10 \\
335 \\
302.4 \\
181.3 \\
189 \\
242.4 \\
60 \\
302.4 \\
16.1 \\
16.1 \\
16.1 \\
23.4 \\
23.4 \\
23.4 \\
23.4 \\
20.8 \\
20.8 \\
20.8\end{array}$ & $\begin{array}{c}43.7 \\
32 / 39 \\
49 \\
45 \\
1.5 \\
36 \\
0 \\
9 \\
45 \\
51.3 \\
35.3 \\
19 \\
19 \\
3 \\
5 \\
49 \\
-36 \\
45 \\
55 \\
49 \\
49 \\
-36 \\
37.3 \\
43 \\
49 \\
-38 \\
2.7 \\
9 \\
35.4 \\
40 \\
-38 \\
38 \\
38 \\
38 \\
35.2 \\
35.2 \\
35.2 \\
35.2 \\
37 \\
37 \\
37\end{array}$ & 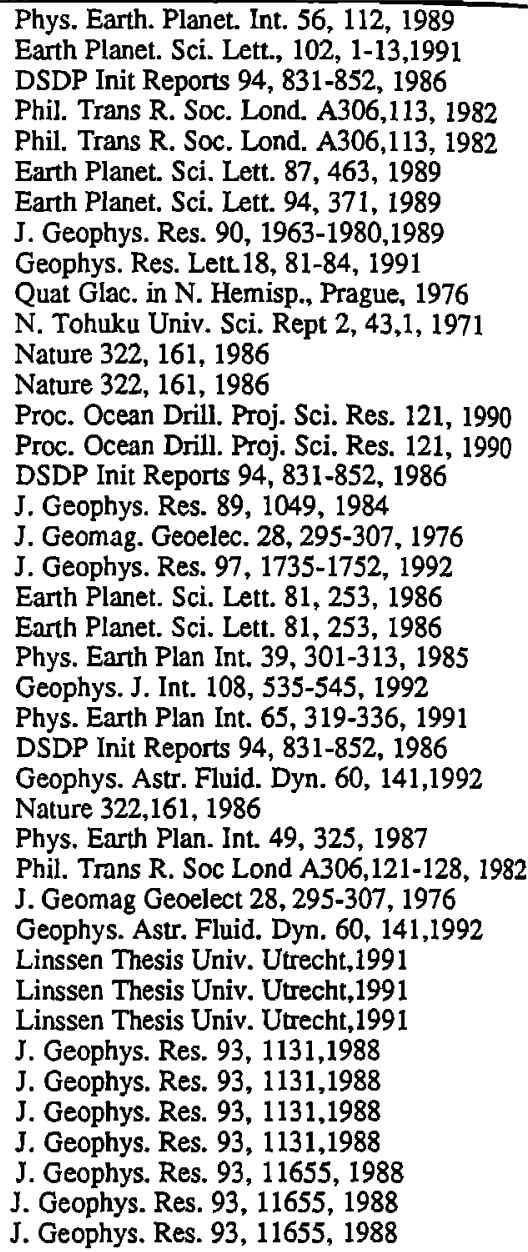 \\
\hline
\end{tabular}

H-B* : Herrero-Bervera

rejected, otherwise the fit is considered satisfactory (see i.e. Batschelet, 1981, for the definition of $\mathrm{U}^{2}$ and for tables of critical values).

Rao's test uses the angular distance between successive data points on the circle. For a uniform distribution the $n$ sample points should be equally distributed on the circle and spaced at $360 / n$. Large deviations from this value indicate non-randomness. When the sample value of the test statistics $\mathrm{U}$ exceeds a critical value $\mathrm{U}(\gamma)$ the null hypothesis can be rejected at the $\gamma$ significance level. Definition of $U$ and tables of critical values can be found in Batschelet [1981].

The Rayleigh test considers the resultant length $\mathrm{R}$ of the unit vectors joining the center of the circle with the individual data points. For a uniform distribution, $\mathrm{R}$ is small, while sufficiently large values of $R$ lead to rejection of the null hypothesis in favour of one-sideness of the parent distribution. The statistics $\mathrm{z}$ used and the corresponding limiting values at different significance levels are given in tables (see i.e. Batschelet, 1981). The Rayleigh test may be misleading for an axial bimodal distribution, because opposed individual unit vectors may average out. A large increase in the value of the $\mathrm{z}$ parameter upon doubling the angles is a clear statistical indication of a bimodal axial distribution of the data.

\section{Results and Discussion}

The results of the statistical analysis are reported in Table 2. Following Valet et al. [1992], we have analyzed separately the intervals $0-2$ my and the entire 0-12 my, because the most recent reversals are unambiguously identified and more than one record is available for each of them from different sites.

For both intervals, the probability that the observed distribution is issued from a uniform probability distribution is very small $(\gamma<0.05)$ so the null hypothesis can be rejected. The rejection of uniformity is at even higher significance levels when the method of doubling the angles is used and all the data are considered. In this case, for 0-12 my we observe an increase in the values of the test parameters from the three tests and particularly of Rayleigh's $z$ parameter. These results are a clear indication for bimodality. This tendency is not marked for the 0-2 my period where the data appear to be distributed more unimodally.

When the 0-12 my interval is considered, the mean angles obtained for the bimodal distribution are $\phi_{1}=120 \pm 28^{\circ}$, and $\phi_{2}=300 \pm 28^{\circ}(2 \sigma)$. These two bands of longitude lie on the Americas and its antipode.

We have repeated the analysis in a common site longitude 


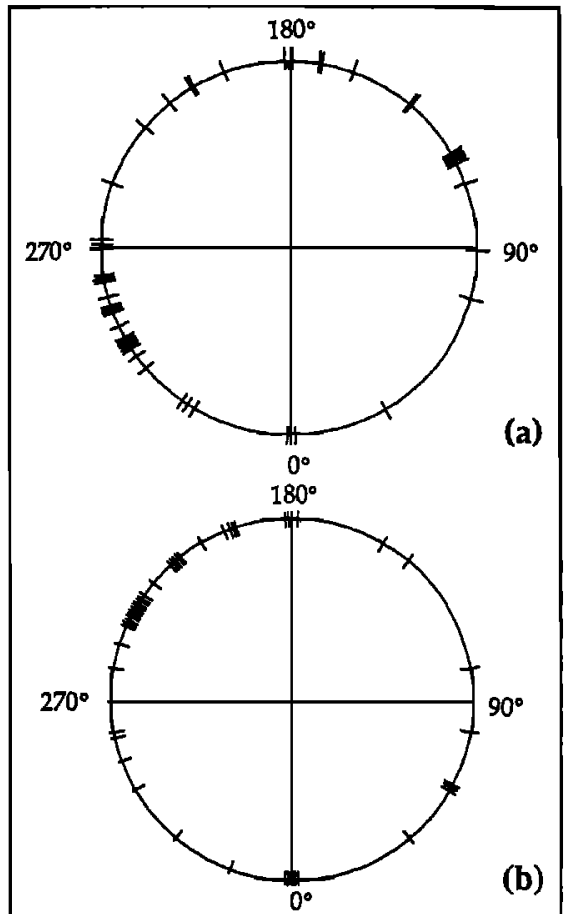

Fig.1. a) Equatorial crossings of the considered reversal paths. b) Same after doubling the angles. Lines of identical longitude are sligtly $\left(3^{\circ}\right)$ separated for a better visual grasp.

frame (Table 3). For the 0-2 my interval, the observed distribution could well arise from a uniform random distribution and no preferential trend is apparent. When the older records are added, the three tests reject the uniform distribution hypothesis and the Rayleigh test shows that there is a tendency for the paths to lie about $\pm 90^{\circ}$ away from the sites. This tendency was also noted by Valet et al. [1992]. The two results (two preferential bands and grouping at $90^{\circ}$ from the site longitudes) are mathematically consistent because the distribution of sampling sites is strongly biased towards the European sites and Europe is $90^{\circ}$ away from the two longitudinal bands, but the physical mechanisms implied are completely different in the two cases. The existence of a preferential $90^{\circ}$ difference between site and VGP-path longitudes would suggest some mechanism related to the

Table 2. The results of the Rayleigh, Rao, and Watson tests for the 0-2 my and the 0-12 my intervals.

\begin{tabular}{lrlrr}
\hline \multicolumn{1}{c}{ Test } & \multicolumn{2}{c}{$\begin{array}{c}0-2 \mathrm{my} \\
\text { [35 paths] }\end{array}$} & \multicolumn{2}{c}{$\begin{array}{c}0-12 \mathrm{my} \\
\text { [50 paths] }\end{array}$} \\
\hline Rayleigh & $\gamma<0.025$ & {$[\mathrm{z}=3.86]$} & $\gamma<0.025$ & {$[\mathrm{z}=3.78]$} \\
angles doubled & $\gamma<0.05$ & {$[\mathrm{z}=3.28]$} & $\gamma<0.01$ & {$[\mathrm{z}=8.48]$} \\
\hline Rao & $\gamma<0.01$ & {$[\mathrm{U}=167]$} & $\gamma<0.01$ & {$[\mathrm{U}=195.4]$} \\
angles doubled & $\gamma<0.025$ & {$[\mathrm{U}=166]$} & $\gamma<0.01$ & {$[\mathrm{U}=216]$} \\
\hline Watson & $\gamma<0.01\left[\mathrm{U}^{2}=0.28\right]$ & $\gamma<0.01$ & {$\left[\mathrm{U}^{2}=0.34\right]$} \\
angles doubled & $\gamma<0.025\left[\mathrm{U}^{2}=0.24\right]$ & $\gamma<0.01$ & {$\left[\mathrm{U}^{2}=0.52\right]$} \\
\hline
\end{tabular}

Table 3. The results of the Rayleigh, Rao, and Watson tests in a common site longitude frame. For the 0-2 my period the observed equatorial crossing-site distances may well arise from a uniform random distribution $(\gamma>0.1)$. For the $0-12$ my interval, on the contrary, the probability that the observations arise from a uniform distribution is very low.

\begin{tabular}{ccc}
\hline & $0-2 \mathrm{my}$ & $0-12 \mathrm{my}$ \\
Test & {$[35$ common site longitude $]$} & {$[50$ common site longitude $]$}
\end{tabular}

\begin{tabular}{|c|c|c|c|c|}
\hline $\begin{array}{l}\text { Rayleigh } \\
\text { angles doubled }\end{array}$ & $\begin{array}{l}\gamma>0.1 \\
\gamma>0.1\end{array}$ & $\begin{array}{l}{[z=2]} \\
{[z=2]}\end{array}$ & $\begin{array}{r}\gamma>0.2 \\
\gamma<0.025\end{array}$ & $\begin{array}{l}{[\mathrm{z}=1.58]} \\
{[\mathrm{z}=4.41]}\end{array}$ \\
\hline $\begin{array}{l}\text { ao } \\
\text { gles doubled }\end{array}$ & $\begin{array}{l}\gamma>0.1 \\
\gamma>0.1\end{array}$ & $\begin{array}{r}{[U=130.8]} \\
{[U=138]}\end{array}$ & $\begin{array}{r}\gamma>0.1 \\
\gamma<0.05\end{array}$ & \\
\hline gle: & $\gamma>0.1$ & {$\left[U^{2}=0.13\right]$} & $\begin{array}{r}\gamma>0.05 \\
\gamma<0.025\end{array}$ & {$\left[U^{2}=0.10\right]$} \\
\hline
\end{tabular}

recording process, the existence of the two preferential bands independent of site longitudes would sustain the hypothesis of mantle-controlled preferred paths.

To investigate this further we have repeated the analysis considering only the 24 records obtained from sites situated outside the interval $30^{\circ} \mathrm{E}$ to $30^{\circ} \mathrm{W}$ longitude. Watson's test then shows that the distribution of the equatorial crossings of this reduced set of records significantly differs from a random uniform distribution. The Rayleigh test also shows that the records are preferentially situated in the $\left(246 \pm 47^{\circ}\right)$ longitudinal band, not significantly different from one of the two preferential sectors. When repeated in a common site longitude frame, this test does not detect any significant preferential distance between site and VGP-path longitudes (a tendency for a distance of $=22^{\circ}$ is not significant). This tendency is barely significant when Watson's test is employed. These results thus suggest that the tendency for European paths to lie at $\pm 90^{\circ}$ from the sites results more likely from the geographical position of Europe than from sedimentary magnetization artefacts.

The results obtained here concern sedimentary formations only. The few volcanic records available from the literature are characterized by much greater scatter and intermediate directions are largely missing, so that it has generally been considered that volcanic records do not yield evidence for any particular geometry of the reversal paths. The most recent studies do, however, reveal some systematics of the reversal process. A recent analysis of the records from the Hawaii and Society Islands hotspots [Hoffman, 1991] has shown that they are characterized by the presence of clusters of transitional directions recorded in different lava flows. When only one record is considered, a cluster could be explained by the variable extrusion rate of the volcano. However, when all the records are considered, the VGPs corresponding to the clusters all reside within a $60^{\circ}$ band of longitude centered near $310^{\circ}$ or on a band centered along a meridian near Western Australia. Thus, the clusters lie well within the two preferential bands defined by sedimentary studies. Also, in the first half of the Steens Mountain transition [Prévot et al., 1985], the path is largely over the Americas. In the second half, there are rapid loops in the VGP paths which may 
provide a record of secular variation during the reversal that would be strongly attenuated in the equivalent sedimentary record. Thus, at least some aspects of the volcanic records are not inconsistent with sedimentary records.

\section{Conclusions}

The results obtained here using circular statistics support the visual impression of a preponderance of transitional VGP paths in the longitudinal sector over the Americas and, to a lesser extent, over its antipode. When the European records are not considered the results still document the preferential band over the Americas sustaining the hypothesis that VGP paths result from real geomagnetic field behaviour and not sedimentary artefacts.

These results are consistent with those discussed elsewhere [Weeks et al., this volume] which conclude that unrealistic sedimentary smoothing would be necessary to deviate VGPs $90^{\circ}$ away from the site. On the other hand, they are inconsistent with those of Valet et al. [1992]. However, it appears that the statistical analysis employed may have led these authors to an incorrect conclusion. When the circular statistics tests are applied to the database of Valet et al. [1992] the results are quite consistent with those obtained here [Laj et al., in press]. Our results are also partly inconsistent with the conclusions of Langereis et al. [1992] who have considered Mediterranean records only. These authors suggest that smoothing of pre- and post-transitional directions is a good candidate for explaining reversal paths, but they do not exclude that the paths might be related to real field features.

Although we are faced with the problem of the paucity of reliable records and of the inhomogeneous distribution of sites, we believe that with the data available today, the hypothesis of mantle-controlled preferred bands of longitude for transitional VGPs should be seriously considered in the study of the mechanisms of the Earth's deep interior.

Acknowledgements: We wish to thank Dr. S. Rao of UCSB for his help in the statistical analysis and Dr. C. Constable for improving the original manuscript. This work was supported by the CEA and the CNRS. Financial support to E. H-B was provided by SOEST-HIG and by NSF grant EAR-896597. This is SOEST-HIG contribution 2986, INSU-DBT-Instabilités contribution 493, CFR contribution 1325.

\section{References}

Batschelet, E. "Circular Statistics in Biology", Mathematics in Biology, series Editor Sibson R., and Cohen, J. E., Academic Press, 1981.

Clement, B. M., Geographical distribution of transitional VGPs: evidence for non-zonal equatorial symmetry during the Matuyama-Brunhes geomagnetic reversal, Earth Planet. Sci. Lett., 104, 48-58, 1991.
Fuller, M., Williams, I. and Hoffman, K. A., Paleomagnetic records of geomagnetic field reversals and the morphology of the transitional fields, Rev. Geophys. Space Phys., 17, 179-203, 1979.

Hoffman, K. A., Long-lived transitional states of the geomagnetic field and the two dynamo families, Nature, 354, 273-277, 1991.

Laj, C., Mazaud, A., Weeks, R., Fuller, M., HerreroBervera, E., Geomagnetic reversal paths, Nature, 35I, 447, 1991.

Laj, C., Mazaud, A., Weeks, R., Fuller, M., HerreroBervera, E., Geomagnetic reversal paths revisited, Nature, in press, 1992.

Langereis, C. G., Van Hoof, A. A. M., and Rochette, P., Longitudinal confinement of geomagnetic reversal paths: sedimentary artefact or true field behaviour, Nature, 358 , 226-229, 1992.

Prévot, M., Mankinen, E. A., Grommé, C. S., and Coe, R., How the geomagnetic field vector reverses polarity, Nature, 316, 230-233, 1985.

Rochette, P., Rationale of geomagnetic reversals versus remanence recording processes in rocks: a critical review, Earth Planet. Sci. Lett., 98, 33-39, 1990.

Tric, E., Laj, C., Jehanno, C., Valet, J. P., Kissel, C., Mazaud, A., Iaccarino, S., High resolution record of the Upper Olduvai Transition from Po Valley (Italy) sediments: support for dipolar transition geometry?, Phys., Earth Planet. Int., 65, 319-336, 1991a.

Tric, E., Laj, C., Valet, J. P., Tucholka,P., Paterne, M. and Guichard, F., The Blake geomagnetic event: transition geometry, dynamical characteristics and geomagnetic signifiance, Earth Planet. Sci. Lett., 102, 1-13, $1991 \mathrm{~b}$.

Valet, J. P., Tucholka, P., Courtillot, V., and Meynadier, L. Paleomagnetic constraints on the geometry of the geomagnetic field during reversals, Nature, 356, 400-407, 1992.

Weeks, R., Fuller, M., and Williams, I., The effect of recording medium upon reversal records, Geophys. Res. Lett. 15, 1255-1258, 1988.

Weeks, R. J., Fuller, M., Laj, C., Mazaud, A., HerreroBervera, E., Sedimentary records of reversal transitions magnetization smoothing artefact or geomagnetic field behaviour?, Geophys. Res. Lett., this volume, 1992.

M. Fuller, Department of Geological Sciences, University of California Santa Barbara, CA 93106 USA.

E. Herrero-Bervera, SOEST - HIG, University of Hawaii, Honolulu, HI 96822, USA.

C. Laj, A. Mazaud, R. Weeks, Centre des Faibles Radioactivités, Laboratoire Mixte CNRS-CEA, Avenue de la Terrasse, 91198 Gif-sur-Yvêttte Cedex, France.

(Received: June 8, 1992

revised: August 17, 1992

accepted: August 17, 1992) 